\title{
Ethical and practical considerations on cancer recommendations during COVID-19 pandemic
}

\author{
CHRISTOS MELIDIS $^{1}$ and MILTIADIS VANTSOS ${ }^{2}$ \\ ${ }^{1}$ Radiation Therapy Department, 20200 Bastia, France; \\ ${ }^{2}$ Faculty of Theology, Aristotle University of Thessaloniki, 54124 Thessaloniki, Greece
}

Received May 22, 2020; Accepted June 19, 2020

DOI:10.3892/mco.2020.2075

\begin{abstract}
National and international authorities and societies have recently published important cancer treatment recommendations in order to propose extra measures that should be taken during the COVID-19 pandemic, such as prioritisation of intend-to-cure treatments and younger patients, omission of non-urgent cases, and reduction of personnel present. These measures raise important ethical considerations, since they prioritise protection of Health Systems and Professionals without seemingly taking cancer patient feelings of stress into consideration. This could lead to an erosion of the physician-patient relationship, which is considered the core element of medical ethics. Moreover, they raise practical concerns about the continuous education of Health Professionals, the status of reference centres and the evaluation of the hitherto cancer treatments.
\end{abstract}

\section{Introduction}

Dealing with COVID-19 pandemic is a global absolute necessity (1) and its priority is fully understood. Unavoidable, yet not desirable, effect of this is the alteration of the course of other diseases, as well as their treatment restriction (2), always in a way that is compatible with the specificities of each. As far as cancer treatment is concerned, national and international recommendations published in March 2020 (3-8) call for extra measures to be taken by the surgical, chemotherapy and radiotherapy (RT) personnel in order to protect themselves and patients alike from being infected by COVID-19. Among others, most recommendations propose the following:

Correspondence to: Dr Christos Melidis, Radiation Therapy Department, CAP Santé, 13 Rue Marcel Paul, 20200 Bastia, France

E-mail: melichristos@hotmail.com

Key words: COVID-19, pandemic, cancer treatment, ethical considerations i) Treatment omission for certain non-urgent cases and all COVID-19 positive patients; ii) Prioritisation for intent-to-cure treatments versus palliative ones; iii) Prioritisation of younger versus older patients (with 65 years of age usually set as the cutoff age); and iv) Reduction of the number of personnel present to as low as reasonably achievable (ALARA), so that the least possible number of patients and personnel are present at a given moment, in order to decrease the chances of COVID-19 infection.

These recommendations indeed correspond to the special conditions that spread of the pandemic imposes on Health Systems and specify restrictions to be taken into consideration by health personnel and administration concerning people management and cancer treatments. While it is not the authors' intention to question the necessity of such recommendations, this article focuses on some ethical considerations that their content may have on cancer patients and some practical concerns that their implementation may bring to health professionals.

\section{Ethical considerations}

It is commonly accepted that Health Services should treat all patients on an equal basis (9). Of course, an equal treatment does not mean same treatment for all, since each disease differs in the ways of dealing with it and terms of affecting patient's quality of life. After all, a disease is never experienced the same exact way by all patients or by a given person throughout the course of their treatment. It is also universally accepted that emergencies impose and justify extraordinary measures, which may deviate substantially from usual medical practice (10). However, patients consider that treatment of their illness at the very moment it occurs is of great importance, since it deprives them of the fundamental good health and makes their life harder. This is even more true in the case of cancer patients, since cancer is perhaps the disease that people fear the most (11), due to its high mortality rate, and alleged painful death. This is why moral and psychological support of cancer patients throughout their illness is of paramount importance. Recently published cancer treatment guidelines focus on the Health System needs and personnel protection, underestimating the psychological needs of cancer patients 
and consequently the importance of trust in the physician and applied medical treatment. In general, good physician-patient relationship is considered the core element in medical ethics at least since the Hippocratic Oath, not only for genuine ethical but also for efficiency reasons. The more the patient trusts the physician and has a positive attitude towards the treatment, the better the results that can be achieved. In other words, a good understanding between physician and patient improves the medical and emotional condition of the patient, leads to better compliance with the treatment and enhance the trust towards the health services $(12,13)$.

However, reduced number of treatment sessions than the ones initially presented to the patients and distinctions based on age criteria and level of emergency are likely to upset cancer patients, make them feel they are being put aside and neglected, despite the imminent risk to their lives. Should one try to put him/herself in their position, he/she will be faced with treating physicians announcing that 'based on new, international guidelines due to the COVID-19 pandemic, some sessions will be postponed and the others will be carried out, but at more sparse intervals, since the pandemic needs to be addressed and personnel protected'. Although justification for these changes could possibly be largely accepted by the public, it is very likely that this kind of explanation may be perceived as unfair and condemnable by cancer patients and relatives. In other words, cancer patients may consider that the Health System regards them as a 'burden' and their treatments should be set aside in order to promote saving human and non-human resources for other efforts that are broadly considered as more important. Such a view is reasonable to cause feelings of anxiety and fear concerning the outcome of their treatments as well as frustration and anger against the Health System, while it could wear down the physician-patient relationship and have a negative impact on the treatment's outcome.

Cancer patient feelings are of course not the only or the best criterion for decision making during the current COVID-19 pandemic context. We believe, however, that they should be taken into account and not without some empathy for these people. After all, societal measures are generally successful only when fully understood and accepted by the vast majority of concerned people. Although in this case neither the necessity nor the purpose of the recommendations are questioned, one may reconsider the proportionality of the proposed measures in terms of personnel contamination risk and negative consequences for cancer patients resulting from different treatment schedules or its postponement. Strengthening the psychological support in view of treatment alterations or cancelations and maintaining the patient's trust and compliance in the medical treatment would also be helpful in order to keep cancer patient morale and hope for full health restoration intact (14). Such a proposal seems at first glance to simply shift the offer of care from Oncologists, Surgical Oncologists and Radiation Oncologists to Psychologists, and therefore merely transfer the pressure from some medical specialties to others. This extra care provision can, in our view, be addressed if the number of people providing psychological and moral support is expanded to also include clergy and volunteers who should, obviously, meet the requirements for such an endeavor.
Especially for religious patients support of a clergyman is generally considered welcomed and important, and that is why the possibility of having such a religious minister in hospitals is accepted in many countries $(15,16)$. Positive effects of this kind of psychological support for cancer patients has been documented in several studies $(17,18)$, but under the extreme circumstances of a pandemic and taking into consideration the expected reduction of the number or postponement of treatments, the importance of this support to these patients becomes, in our estimation, even greater. Especially for Christian Ethics, this kind of help to the suffering fellow human being is of the highest moral duty and its importance goes beyond the psychological aspect and the aim of therapy, embracing also a certain spiritual dimension: the disease highlights the weakness of human nature, providing at the same time fertile ground for humans to reconsider their lives and actions, forgive and reconcile with people with whom their relationships have been ruptured, and draw strength, optimism, peace, and tranquility from their faith and hope in God. But also for non-religious patients, psychological support and solidarity by psychologists and volunteers alike can be particularly valuable under the prevailing conditions of this pandemic period.

Ethical considerations on cancer recommendations during COVID-19 pandemic concerning the maintenance of a trust-based physician-patient relationship includes the physician's duties as well. Reduction of the number of personnel present to ALARA could represent more stressful working conditions than usual, resulting in augmented fatigue, less patience and burnout risk. These, in their turn, could potentially affect the quality of the provided services and increase accidents, since most accidents in cancer therapy are associated, among other factors, with too few health professionals present $(19,20)$. Based on these, the laws in most cases foresee the constant presence, as an example among many specialties, of 'at least two (2) Medical Technologists in RT per Linear Accelerator'. However, there have been national Competent Authorities (CA; for example in France) that have temporarily removed this requirement, at least for what is considered as simple techniques of irradiation. People tend to be anxious and worried when going to public services running on minimum personnel assuring only the essential services, as is the case during strikes. Thus, it would be difficult to convince cancer patients and their relatives that cancer treatment services running on ALARA are of equivalent quality as before, something that is likely to add yet another stressing factor to their lives.

\section{Practical considerations}

During the pandemic travel is generally not allowed or extremely limited, leading most national and international congresses to be postponed or cancelled, and all progress on cancer research to be communicated only via scientific articles. In Belgium, as is the case in many European countries, radiation practitioners need continuous education 'points' in order to renew their authorizations to exercise, as described in the relevant Royal Decree (21) and Technical Regulations (22). During this period the Belgian CA on radiation (FANC) was forced to prolong the before mentioned authorizations without first summing their points of continuous education (23). Health 
Professionals, mostly those working on a freelancer basis (mainly but not only dentists) and, thus, those paying their continuous education out of their pockets, could see this as an opportunity to avoid congress participation also out of the pandemic era.

Although reading more publications than before will not necessarily interfere too much with the already overloaded program of practitioners, there is always a small chance that important research might be overlooked, while webinars, that were thought by many to be anyway the future of scientific communication, are still lacking administrative and technical support within most major scientific societies. A possible temporary solution could be that scientific societies create specific working groups that will keep an eye on all relevant publications and will broadly communicate the most important ones to their members, while trying to search for feasible solutions on holding webinars.

Moreover, some recommendations seem to be contradictory, maybe even creating a feeling of non-equal, or even unfair, behavior from CAs and scientific societies towards their members and health professionals. This seems to be the case, for example, in France, where external audits must take place annually (24), during which a certified auditor, who is usually a Medical Physicist (MP), makes an official visit to the RT department and checks if the internal Quality Assurance (QA) controls have indeed taken place according to the national regulations. These external audits are mainly, if not exclusively, administrative and based on printed or online documentation provided by the RT department. The internal QA procedures checked by the external auditor are commonly accomplished by MPs or Dosimetrists, who have been clearly informed by their respective scientific society that during the pandemic the minimum frequency and content of QA remains unchanged, even if the exact same recommendations propose the physical presence of ALARA MPs (25). However, the French CA has allowed its temporary postponement (24), even if this could obviously take place remotely, given the difficulty in traveling and in order to protect the auditors. In other words, less MPs than before need to conduct the same amount of QA, even if 'extra hours of work might be necessary', the external audit of which will wait until the pandemic is over.

Given points i), ii) and iii) of the recommendations presented at the beginning of the article, it is expected that most cancer treatment services will slowly experience a decline in their number of patients. However, some national and international societies demand that a minimum number of cases per cancer site per year is reached, so that centers and doctors are considered as 'reference'. Should the duration of the pandemic continue to extend, it is possible that this number is not reached. On the contrary, other centers and doctors could eventually decide to keep the same number of patients as before, to treat or not being ultimately a medical decision, or even be obliged to augment their numbers, since patients that would normally be treated by the reference centers will just seek to be treated elsewhere. Consequently, it might now be these non-refusing centers and doctors that could reach the desired number of patients and, thus, be considered as reference and/or opinion-leaders once the pandemic is over. This change might be inevitable or even insignificant, but needs at least to be kept at the back of one's mind when deciding to fully implement the recommendations.

Medicine is an evidence-based science, constantly evolving and improving by research and new data evaluation. In order to offer the best possible treatment, health professionals and researchers constantly search for the ideal hypofractionation scheme, least total dose that is sufficient, irradiation field sizes, necessity of boosts, etc. It would be difficult even to look for answers to these questions during the COVID-19 period, but although these recommendations are temporary, they imply that treatment results concerning overall survival with or without hypofractionation and with or without boost will not be dramatically different amongst them. Boost omission, regardless of hypofracionation, leads to lower total irradiation dose received by the tumour (or tumour bed). If this is deemed feasible, as shown at least for some breast cases (26), the view that boost sessions still practiced is considered overtreatment, regardless of whether they take place within or out of the pandemic era, will be reinforced. At the same hand, if hypofractionation and/or boost omission prevail, the total number of sessions a patient will have and, thus, the total number of patients per working day a RT department has will decrease. If ALARA personnel carrying less sessions than usual is not considered essentially worse nor more dangerous, the higher management of hospitals will be reluctant to return to the before the pandemic human resources. This situation, in its turn, might be cost-effective, but should not be implemented without some solid prospective proof of its sustainability also during normal periods.

\section{Conclusions}

Cancer treatment recommendation measures published recently under the COVID-19 pandemic era seem not to be taking cancer patient feelings and morale into account, endangering the desired trust-based physician-patient relationship. In addition to that, fully following the recommendations could create practical issues ranging from questioning continuous education to concerns about potential overtreatments.

As is the case with every crisis, COVID-19 pandemic could also create opportunities: this might be the best time to empower the already proven usefulness of Psychologists and to make better use of the help that clergymen and volunteers can offer to cancer patients. In parallel, it could revive the discussion on cost-effectiveness in terms of personnel, cancer treatment techniques and best care strategies both under normal and pandemic circumstances.

\section{References}

1. World Health Organisation (WHO): WHO characterizes COVID-19 as a pandemic. https://www.who.int/emergencies/ diseases/novel-coronavirus-2019/events-as-they-happen. Accessed March 11, 2020.

2. Tsamakis K, Rizos E, Manolis AJ, Chaidou S, Kympouropoulos S Spartalis E, Spandidos DA, Tsiptsios D and Triantafyllis AS: COVID-19 pandemic and its impact on mental health of healthcare professionals. Exp Ther Med 19: 3451-3453, 2020.

3. French Hospital Federation (FHF): COVID-19 et Cancers Solides: Recommandations. FHF, Paris, 2020. https://www.fhf. $\mathrm{fr} /$ Offre-de-soins-Qualite/ Organisation-de-l-offre-de-soins/ COVID-19-et-Cancers-Solides-Recommandations. Accessed May 29, 2020. 
4. Simcock R, Thomas TV, Estes C, Filippi AR, Katz MA Pereira IJ and Saeed H: COVID-19: Global radiation oncology's targeted response for pandemic preparedness. Clin Transl Radiat Oncol 22: 55-68, 2020.

5. Coles CE, Aristei C, Bliss J, Boersma L, Brunt AM, Chatterjee S, Hanna G, Jagsi R, Person OK, Kirby A, et al: International guidelines on radiation therapy for breast cancer during the COVID-19 pandemic. Clin Oncol 32: 279-281, 2020.

6. Filippi AR, Russi E, Magrini SM and Corvò R: COVID-19 outbreak in northern Italy: first practical indications for Radiotherapy Departments. Int J Radiat Oncol: doi: https://doi. org/10.1016/j.ijrobp.2020.03.007.

7. European Society of Surgical Oncology (ESSO): ESSO Statement on COVID-19. ESSO, Brussels, 2020. https://www.essoweb.org/ news/esso-statement-covid-19/. Accessed May 29, 2020.

8. Cancer Research UK: Coronavirus (COVID-19) and cancer treatment. https://www.cancerresearchuk.org/about-cancer/ cancer-in-general/ coronavirus/cancer-treatment. Accessed May 29, 2020.

9. Burger R: A promising approach to identifying health system discrimination and bias. Lancet Glob Health 7: E546-E547, 2019.

10. Committee on Guidance for Establishing Crisis Standards of Care for Use in Disaster Situations; Institute of Medicine: Legal Issues in Emergencies. In: Crisis Standards of Care: A Systems Framework for Catastrophic Disaster Response. National Academies Press (US), Washington, DC, 2012.

11. Vrinten C, van Jaarsveld CHM, Waller J, von Wagner C and Wardle J: The structure and demographic correlates of cancer fear. BMC Cancer 14: 597, 2014.

12. Goold SD and Lipkin M: The doctor-patient relationship. J Gen Intern Med 14, S26-S33, 1999.

13. Brody H: The Physician - patient relationship. In: Medical Ethics. Veatch RM (ed). 2nd edition. Jones and Bartlett Publishers, pp75-102, 1997.

14. Spiegel D, Bloom JR, Kraemer H and Gottheil E: Psychological support for cancer patients. Lancet 2: 1447, 1989.

15. Kofinas S: The priest's ministry at the hospital. In: Introduction to Pastoral Ministry in Health. Therapeian Prosagontes, Athens, pp171-203, 2011.

16. Eftichiadis Ch: Institution of the Hospital Pastor. Official Website of the Church of Greece, 1999. http://ecclesia.gr/greek/ holysynod/commitees/pastoral/nosokomeio_efimerios.html.

17. Balboni TA, Vanderwerker LC, Block SD, Paulk ME, Lathan CS, Peteet JR and Prigerson HG: Religiousness and spiritual support among advanced cancer patients and associations with end-of-life treatment preferences and quality of life. J Clin Oncol 25 555-560, 2007.
18. Balboni T, Balboni M, Paulk ME, Phelps A, Wright A, Peteet J, Block S, Lathan C, Vanderweele T and Prigerson H: Support of cancer patients' spiritual needs and associations with medical care costs at the end of life. Cancer 117: 5383-5391, 2011.

19. Ford EC and Evans SB: Incident learning in radiation oncology: A review. Med Phys 45: e100-e119, 2018.

20. International Atomic Energy Agency (IAEA): Radiotherapy in Cancer Care: Facing the Global Challenge. IAEA, Vienna, 2017. https://www.iaea.org/publications/10627/radiotherapy-in-cancercare-facing-the-global-challenge.

21. Agence fédérale de Contrôle Nucleaire (AFCN): Arrêté royal relatif aux expositions médicales et aux expositions à des fins d'imagerie non médicale avec des équipements radiologiques médicaux. https://afen.fgov.be/fr/system/files/20200220 publicatie-kb-med.pdf. Accessed February 13, 2020.

22. Federaal Agentschap voor Nucleaire Controle (FANC): Règlement technique fixant le barème d'attribution pour les activités de formation continue de l'expert agréé en radiophysique médicale. https://fanc.fgov.be/nl/system/files/2020-03-10-permanente-vorming-msf.pdf. Accessed March 3, 2020

23. Agence fédérale de Contrôle Nucleaire (AFCN): Prolongation automatique de l'autorisation d'utilisation des rayons $\mathrm{X}$ à des fins d'imagerie médicale et exemption de formation continue pour l'année 2020. AFCN, Brussels, 2020. https://www.gbs-vbs.org/ fileadmin/user_upload/e-specialist/2020/EDR_Covid_19_2020_ FR_signe.pdf. Accessed April 7, 2020.

24. Agence Nationale de Sécurité du Médicament et des Produits de Santé (ANSM): Contrôle qualité des dispositifs médicaux. ANSM, Saint-Denis Cedex, 2020. https://www.ansm.sante.fr/Activites/ Maintenance-et-controle-qualite-des-dispositifs-medicaux/Contro le-qualite-des-dispositifs-medicaux/(offset)/0. Accessed April 24, 2020.

25. Société Française de Physique Médicale (SFRO): Epidémie de COVID-19: Recommandations à l'usage des professionnels de l'Oncologie Radiothérapie. https://www.sfpm.fr/sites/www.sfpm. $\mathrm{fr} /$ files/Bibliotheque/Travaux_en_cours/Conseil_administration/ recommandations_covid_19_sfro_v2.pdf. Accessed March 19, 2020.

26. Bartelink H, Maingon P, Poortmans P, Weltens C, Fourquet A, Jager J, Schinagl D, Oei B, Rodenhuis C, Horiot JC, et al; European Organisation for Research and Treatment of Cancer Radiation Oncology and Breast Cancer Groups: Whole-breast irradiation with or without a boost for patients treated with breast-conserving surgery for early breast cancer: 20 -year follow-up of a randomised phase 3 trial. Lancet Oncol 16: 47-56, 2015. 